\title{
Experiências de dor e lesão no desporto feminino
}

\author{
Maria Claudia Pinheiro* \\ Nuno Jorge Pimenta** \\ Natália Pereira*** \\ Sebastião Votre ${ }^{* * * *}$
}

\begin{abstract}
Resumo: No desporto atual cada vez mais se valoriza a vitória diminuindo a importância atribuída à simples participação desportiva. Com o objetivo da vitória a todo custo, muitos são os atletas que apresentam grande prontidão para treinar e competir com dor e lesão. A maioria dos estudos abordando a problemática da dor e da lesão tem-se centrado nas experiências e vivências de dor e lesão de atletas do gênero masculino, nas pressões que atuam sobre esses atletas, levando-os a sujeitarem os seus corpos à dor e lesão. No entanto, este fenômeno da dor e da lesão não é estranho às mulheres atletas. Assim, este trabalho tem como principal objetivo compreender as razões que levam atletas do gênero feminino, praticantes de diferentes modalidades, a aceitarem e tolerarem a dor, e a treinarem e competirem enquanto lesionadas. É também nosso propósito averiguar acerca das estratégias utilizadas por essas atletas para gerir a dor e/ou lesão. Para a recolha da informação, efetuamos 7 entrevistas semiestruturadas a atletas das seguintes modalidades: natação, voleibol, handebol, judô, ginástica, futebol e atletismo. As mulheres envolvidas neste estudo, com idades compreendidas entre os 18 e os 26 anos, foram escolhidas pelo fato de, no momento da investigação, ainda se
\end{abstract}

\footnotetext{
"Doutorada em Sociologia do Desporto pela Universidade de Leicester, Inglaterra. Professora auxiliar no Departamento de Educação Física do Instituto Superior da Maia (ISMAI). Investigadora no Centro de Investigação em Desporto, Saúde e Desenvolvimento Humano (CIDESD). Email:pinclaudia@gmail.com

"Mestre em Sociologia do Desporto pela Universidade de Chester - Inglaterra. Doutorando em Sociologia do Desporto na Universidade de Loughborough, Inglaterra. Membro colaborador no Centro de Investigação em Desporto, Saúde e Desenvolvimento Humano (CIDESD). Bolseiro da Fundação para a Ciência e Tecnologia (FCT). E-mail: nj.pimenta@gmail.com

"'Licenciada em Educação Física e Desporto pelo Institituto Superior da Maia (ISMAI) E-mail: nataliajesuspereira@gmail.com

"Doutorado em Letras pela PUC-RJ. Pesquisador e bolsista de produtividade do CN. Docente na Universidade Gama Filho - sebastianovotre@yahoo.com
} 
encontrarem em atividade. A informação obtida foi submetida à técnica de análise de conteúdo. Após análise dos dados verificamos que durante o período em que se encontravam lesionadas as atletas referiram sentir-se frustradas, com medo e sem autoestima. Esconder, omitir e esquecer a dor e a lesão foram as estratégias apontadas pelas atletas para gerir a dor e a lesão. No presente estudo, tal como em outros estudos já realizados, identificamos e analisamos uma cultura de risco no desporto de elite que tende a normalizar a dor e a lesão.

Palavras chave: dor e lesão, desporto feminino, performance

\section{INTRODUÇÃo}

O desporto nos dias de hoje caracteriza-se por uma elevada competitividade a qual está associada, entre outros aspectos, a processos de politização e comercialização do desporto (WADDINGTON, 2004; MURPHY; WADDINGTON, 1992). Cada vez mais é atribuída uma maior importância à vitória e a todas recompensas associadas, conduzindo a uma diminuição da importância atribuída à simples participação desportiva. Os atletas, ao estarem envolvidos e ao fazerem parte de uma vasta rede de interdependências, tendem a ser pressionados para apresentarem bons resultados, independentemente do modo como os possam atingir. Este fato leva a que atletas de ambos os gêneros se predisponham a inúmeros sacrifícios, os quais podem ser observados na vontade dos atletas para treinarem cada vez mais horas, de uma forma cada vez mais intensa, e também no empenho cada vez mais elevado durante a competição (CHARLESWORTH; YOUNG, 2004; CHARLESWORTH; YOUNG, 2006; LISTON et al., 2006). Porém, esta prontidão e empenho têm as suas repercussões ao nível da saúde dos atletas. Mais concretamente, tal situação conduz a um aumento da predisposição para desenvolverem lesões de sobrecarga e de fadiga, as quais com o tempo se podem tornar permanentes. Com o objetivo da vitória a todo o custo, muitos são os atletas que apresentam uma grande prontidão para treinar e competir com dor e/ou lesão (HOWE, 2004; LOLAND, SKIRSTAD; WADDINGTON, 2006; YOUNG, 2004; WADDINGTON, 2000). 
Pode-se afirmar que no contexto desportivo está presente uma cultura de risco a qual, segundo Howe (2004), normaliza e glorifica o risco como sendo uma componente natural do desporto. Esta ética desportiva é, como refere Young (2004: 5), "um valor presente em muitas subculturas desportivas, o qual encoraja atletas a lutar pela distinção, a fazer sacrifícios, a jogar com dor e a aceitar poucos limites na sua busca pelo sucesso, espírito de equipe e estatuto". Os atletas que se predispõem a competir e a treinar lesionados tendem a ganhar o respeito dos restantes elementos da configuração desportiva e são vistos como exemplos a seguir.

De acordo com Roderick, Waddington e Parker (1999) muitas vezes são os próprios atletas que persistem em treinar e competir com dor. Fazem-no por questões financeiras, assim como por medo de perderem o seu lugar nas equipes ou nas seleções, ou porque a equipe tem um jogo importante e necessita do seu contributo. Mas para além dos próprios atletas existem outros significantes que exercem forte impacto nas suas decisões. Os treinadores são um dos agentes que exercem grande pressão sobre os atletas. O sucesso e bom desempenho dos treinadores tende com frequência a ser visto através dos resultados conquistados o que, de certo modo, os leva a agir sobre os atletas no sentido de os pressionarem a treinar e a competir com dor e/ou lesão. De acordo com Liston et al. (2006), muitas vezes os treinadores conversam com os seus atletas tentando encorajá-los a esconder a dor e as lesões, com o argumento de que não apresentam a atitude correcta se assim não o fizerem. Para além dos treinadores, também os colegas do grupo de trabalho bem como os diretores tendem a olhar para os atletas lesionados com alguma suspeita e cepticismo. Tal fato coloca "pressões" sobre os atletas no sentido de os levar a agir de formas que "não agiriam se não estivessem sob compulsão" (ELIAS, 1980, p.102).

Ainda que os atletas profissionais sejam aqueles que tendem a ser mais pressionados para apresentarem bons resultados, pode-se afirmar que esta cultura de risco não é exclusiva do desporto profissional ou de elite, bem como não é exclusiva do desporto masculino (LISTON et al., 2006; MAGUIRE; PIKE, 2003. Também 
as mulheres experimentam, reagem e têm que gerir as dores e as lesões. Contudo, o estudo desta temática no desporto feminino ainda se encontra na sua infância. Poucos estudos se têm realizado abordando esta problemática e quando nos reportamos a Portugal pode-se mesmo afirmar que, sob o ponto de vista sociológico, estes estudos são inexistentes.

Com efeito, muitos dos estudos realizados em Portugal sobre a temática da lesão no desporto incidem mais numa análise médica, mais concretamente no tipo de lesões mais frequentes nas diferentes modalidades esportivas, na importância da prevenção de lesões no desporto e na recuperação de lesões (AMARAL, SANTOS; FERREIRINHA, 2009; REGO, REIS; OLIVEIRA, 2007; DOMINGUES, 2008).

Além de Liston et al. (2006), também outros autores (CHARLESWORTH; YOUNG, 2004; CHARLESWORTH; YOUNG, 2006; LISTON et al., 2006), apontam que, tanto homens como mulheres atletas parecem acreditar que a dor e a lesão são uma parte integrante do desporto. Desde cedo, independentemente do gênero, os atletas aprendem a desenvolver aquilo que se pode designar por uma 'atitude correcta' (CHARLESWORTH; YOUNG, 2006). Isto é, uma atitude que envolve a normalização do risco, da dor e da lesão. Ainda que desenvolvendo estratégias similares para gerir a dor e/ou lesão, segundo Charlesworth e Young (2006), os atletas tendem a lidar com a dor de um modo mais privado, enquanto que as atletas tendem a falar mais abertamente com treinadores e outros significantes acerca das suas dores e lesões. Tal aspecto é evidenciado por Nixon:

De uma forma geral, as pessoas expressam os significados atribuídos às suas dores e lesões através de mensagens culturais consoante as redes de interdependências a que estão expostos. Assim, a configuração desportiva poderá influenciar a forma como os atletas interpretam e reagem às dores e/ou lesões. (NIXON, 1996, p.78). 
Tanto homens como mulheres atletas adoptam técnicas similares para neutralizarem a dor, que vão desde esconder, negar e desrespeitar a dor, assim como até despersonalizar as manifestações físicas da dor, ou seja, tratar as partes lesionadas como se não fossem suas (CHARLESWORTH \& YOUNG, 2004; CHARLESWORTH \& YOUNG, 2006; YOUNG et al., 1994 apud LISTON, 2006).

Esconder a dor (faz parte da introdução?

Esconder, disfarçar a dor são estratégias frequentemente adoptadas por atletas de ambos os gêneros para lidarem com a dor e/ou lesão. Sendo a dor e a lesão vistas como algo com conotação negativa, como um verdadeiro inconveniente por parte dos treinadores, colegas e até público, os/as atletas tendem a ocultar a dor e/ou a lesão para assim evitarem julgamentos ou críticas. Os treinadores, em particular, tendem a ser bastante impacientes e muito críticos em relação aos atletas lesionados. Como tal, frequentemente, os/as atletas tendem a esconder a dor para evitarem os olhares, os comentários e as críticas dos restantes membros da configuração desportiva.

Desrespeitar a dor

Atletas de ambos os gêneros tendem a adoptar uma atitude de indignação ou ressentimento para com as partes do corpo que se encontram lesionadas (CHARLESWORTH; YOUNG, 2006). Frequentemente recorrem a analgésicos para suportarem a dor, negligenciando muitas vezes os efeitos que tais substâncias terão sobre a sua saúde a longo prazo. Tal fato pode ser observado no discurso de uma atleta entrevistada por estes dois autores:

Eu sabia que não me iria fazer nenhum bem, mas também sabia que se quisesse continuar a competir eu tinha de alguma forma que adormecer a dor. $\mathrm{O}$ meu treinador disse-me que a melhor forma seria através de injecções de cortisona. Porém, uma vez passado o seu efeito, eu ficaria com imensas dores, se não iguais ainda pior que antes, portanto parei de as tomar. Elas conseguiam parar a dor e ajudavam- 
me a lidar com ela durante algum tempo, mas não faziam a lesão ficar melhor (SANDRA. apud CHARLESWORTH; YOUNG, 2006, p. 96)

Despersonalizar a dor

Pelo fato de as lesões serem mal recebidas ou compreendidas na cultura desportiva, os/as atletas tendem a geri-las de uma forma intensa e privada (YOUNG; WHITE, 1995 apud CHARLESWORTH; YOUNG, 2006). De acordo com Charlesworth e Young (2006), os atletas de ambos os gêneros tendem a utilizar técnicas de despersonalização, com o intuito de conferirem algum sentido à dor provocada por lesões. É neste contexto que alguns atletas, para além de se referirem a sentir-se "enganados" pelas suas lesões, mencionam tratá-las de uma forma impessoal. Ainda segundo estes autores, os atletas referem-se às suas lesões como sendo "arranjadas", "remendadas", "congeladas" etc, pois reconhecer ou admitir a responsabilidade das mesmas significaria admitirem uma fraqueza pessoal.

Neste contexto, este trabalho teve como principal objetivo compreender as razões que levam atletas do gênero feminino, praticantes de diferentes modalidades, a aceitarem e tolerarem a dor, e a treinarem e competirem enquanto lesionadas. Foi ainda nosso propósito averiguar acerca das estratégias utilizadas por estas atletas para lidar com a dor e/ou lesão.

\section{Metodologia}

Foram entrevistadas sete atletas de diferentes modalidades. A escolha das modalidades não foi porém aleatória. Seguindo a metodologia utilizada por Charlesworth e Young (2006) as modalidades foram escolhidas por representarem vários tipos de desportos e como tal apresentarem características diferentes. Mais especificamente, foram seleseleionadas modalidades representando desportos de contacto coletivos (andebol) e individuais (judo); desportos de não contacto coletivos (voleibol) e individuais (natação); desportos tradicionalmente masculinos (futebol); desportos tradicionalmente 
considerados femininos (ginástica de trampolins). Foi ainda efetuada uma entrevista a uma atleta do atletismo por ser uma modalidade onde a dor surge no decorrer da própria competição, mais em particular nas provas de longa distância onde, muitas vezes, se torna necessário ter de suportar a dor para terminar a prova ${ }^{1}$. As mulheres envolvidas neste estudo tinham idades compreendidas entre 18 e 26 anos, eram atletas amadoras e todas elas pertenciam à seleção nacional da respectiva modalidade. A prática destas atletas variava entre 6 e 11 anos. Um dos critérios de seleção para a inclusão das atletas era ainda se encontrarem em atividade no momento de realização do estudo. Todas as entrevistadas, no momento da investigação, já tinham passado pela situação de treinar e/ou competir com lesão e todas mencionaram terem continuado a treinar e/ou competir apesar das lesões, que iam desde luxações nos ombros, a rupturas de ligamentos nos joelhos, bursites nos ombros e fascites plantares.

O instrumento utilizado para a recolha de informação foi a entrevista semi-estruturada. A utilização de um instrumento desta natureza tem, segundo Green (1999) um maior potencial, do que é habitualmente reconhecido, de extrapolação do particular para o geral. Desta forma, a infomação recolhida através deste instrumento poderá permitir-nos identificar padrões, que não são apenas peculiares a um só indivíduo ou grupo mas são partilhados, num maior ou menor grau, por pessoas que vivenciam uma situação social comum. Não deveremos considerar os indivíduos singulares, a humanidade ou a sociedade como seres estáticos e separados. Pelo contrário, devemos compreender os grupos interdependentes de indivíduos e as transformações que ocorrem nas suas redes de interdependência a curto e/ou longo prazo. Apesar dos dados recolhidos em cada entrevista serem únicos e representarem as experiências e as perceções de um indivíduo, não deveremos considerar o informante como um indivíduo isolado. Ele pertence a uma configuração desportiva interagindo, direta ou indiretamente, com os outros

${ }^{1}$ Modalidades de cada entrevistada: E1 - andebol; E2 - atletismo; E3 - futebol; E4 - judo; E5 natação; E6 - ginástica de trampolins; E7 - voleibol 
membros dessa configuração. As ações, pensamentos e experiências de um indivíduo não devem, então, ser vistas como isoladas e desligadas dos outros elementos da configuiração desportiva. Mais ainda, os nossos pensamentos e atos só podem ser adequadamente compreendidos se enquadrados nas redes de interdependência que mantemos com outros. Tendo isto em consideração, poderemos ser capazes de generalizar, num maior ou menor grau, a informação recolhida nas entrevistas semi-estruturadas.

Foi elaborado um roteiro integrando questões que se centravam em torno das experiências de treino/jogos/competições com dor e lesão; comportamentos e atitudes face à dor e à lesão e estratégias para lidar com a dor e a lesão. Ainda que utilizando um conjunto prédefinido de questões, durante a entrevista foi possível alterar a ordem bem como acrescentar questões de forma a obter mais informações relativamente aos assuntos que iam sendo abordados. Isto significa que uma entrevista podia ser diferente das restantes no que respeita à ordem e ao número de questões. As entrevistas foram gravadas e posteriormente transcritas, sendo em seguida devolvidas às atletas para estas confirmarem as informações prestadas. A informação obtida foi submetida à técnica de análise de conteúdo. A construção do sistema de categorias foi efetuada à priori e à posteriori. Assim, as categorias treinar/competir com dor e/ou lesionada; sentimentos em relação à dor; estratégias para gerir a dor e a lesão; pressões exercidas por outros significantes (treinadores e colegas) foram estabelecidas à priori, com base na revisão de literatura; já as categorias ambição/reconhecimento/sucesso e camaradagem foram estabelecidas à posteriori pois emergiram da análise do discurso das entrevistadas.

\section{ApresentaÇãoe discussão de resultados}

\subsection{TREINAR E COMPETIR COM DOR E/OU LESÃO}

Segundo estudos realizados (LISTON et al., 2006; RODERICK, 2006), são muitos os atletas que ao longo das suas carreiras desportivas já treinaram e/ou competiram com dor e/ou 
lesão. Kotarba (1983 apud NIXON, 1993), sugere mesmo que a participação desportiva tende a ser acompanhada por dor crónica ou frequentes lesões.

Este fato foi relatado por quase todas as nossas entrevistadas quando questionadas sobre se já tinham treinado e competido com dor e lesão.

[...] quando tive uma rotura de ligamentos no joelho, durante a fase de recuperação, tinha dor e treinava na mesma. (E3)

[...] neste momento por exemplo, tenho uma dor nos ombros, porque tenho bursite nos ombros e são umas dores horríveis. (E5).

Através do discurso das nossas entrevistadas, é possível verificar que treinar e/ou competir com dor e ou lesão é considerado como algo normal, como fazendo parte integrante do desporto. Podese afirmar que as atletas, ao treinarem e/ou competirem com dor e/ ou lesão, estão dispostas a colocar em risco o desenvolvimento de lesões permanentes. Por outras palavras, estão dispostas a colocar os seus corpos em risco.

\subsection{Sentimento EM RELAÇÃo A dOR}

A dor é um alerta sensorial inerente ao corpo humano, o qual geralmente indica que algo de anormal poderá estar a acontecer, funcionando muitas vezes como um instinto de defesa primário. Porém, no contexto desportivo, a dor pode ser uma experiência que signifique um auto-desenvolvimento, ao invés de ser sentida como um trauma. Os limites do corpo, ao serem explorados, originam um "outro" tipo de dor "a dor da carga dos treinos", contudo não implicando algum tipo de lesão. Num estudo realizado com atletas americanos, estes revelaram que a busca da dor, para ultrapassarem os limites do corpo, é uma forma de procurarem a sua identidade (ROESSLER, 2006). São então definidos dois tipos de dor: a boa e a má. A má surge associada ao aparecimento de lesões, enquanto 
que a boa é a que surge devido às cargas intensas dos treinos. Roessler (2006) refere ainda que a dor é algo que está inerente ao 'pacote' da competição. O desporto implica treinar, exercitar e movimentar o corpo e isso pode provocar dor, mas também pode significar que está a ocorrer uma melhoria ao nível da performance.

Quando atletas são questionados acerca da dor da fadiga, tendem a descrevê-la como algo positivo, pois significa que estão a aumentar a sua força (BALE, 2006). Este sentimento foi de certo modo evidenciado por algumas das nossas entrevistadas. Quando questionadas sobre se consideravam normal a dor resultante dos treinos, as entrevistadas $n^{\circ} 1, n^{\circ} 2$ e $n^{\circ} 4$ referiram que esta é algo natural e mesmo indispensável para a melhoria da performance.

Acho que é boa, e é normal, quando estou muito tempo parada, ou quando faço um treino intenso, é normal, é sentir que os músculos estão a evoluir e assim é da maneira que nós sentimos que nos esforçamos no treino e que puxamos por nós e sabemos que para a próxima vez já não teremos essas dores quando fizermos um treino da mesma intensidade. (E1).

Acho que é normal dores musculares e acho que é bom. É sinal que o treino está a entrar. (E2).

Mesmo antes de uma prova. Uma pessoa tem de sentir que treinou bem, e o fato de acabarmos com um bocado de dor, faz com que uma pessoa sinta que treinou bem. (E4).

Contudo, convém referir que a entrevistada $\mathrm{n}^{\circ} 5$ se manifestou de forma contrária, afirmando não conviver bem com a dor e particularmente com a dor resultante dos treinos.

Não, é assim, eu não consigo lidar muito bem com a dor. E por isso, sou capaz de treinar uma semana muito bem, com treinos bi-diários, e na seguinte ter de parar um dia [...] depois para voltar outra vez à mesma carga de treinos é terrível. Então volto a sentir dores musculares e fico com lesões, tenho de fazer tratamentos à noite e tudo mais. É complicado aguentar a dor durante o treino. (E5). 
Apresentar a dor como algo benéfico e normal parece algo absurdo, porém, a elevada competitividade desportiva existente no desporto atual tende a normalizar a dor bem como a ideia de que esta parece ser algo indispensável e mesmo necessário para uma melhoria da performance.

\subsection{ESTRATÉGIAS PARA LIDAR COM A DOR E LESÃO}

As mulheres atletas, tal como os seus companheiros do gênero masculino, são encorajadas a desenvolver uma atitude que as leva a entender uma séria lesão desportiva como algo pouco importante (CURRY; STRAUSS, 1994). Desde muito jovens, os/as atletas aprendem a normalizar a dor e a aceitar treinar e competir com dor e lesões como sendo parte integrante de uma vida ligada ao desporto (RODERICK, WADDINGTON; PARKER, 1999). Este fato surgiu de forma bem evidente no discurso de algumas das nossas entrevistadas, quando questionadas sobre o que pensam acerca do treino ou competição com lesão:

As lesões são as coisas mais normais num atleta, então eles dizem-me sempre isso, que é para nós não nos habituarmos mal e mesmo que tenhamos lesões mais fracas continuemos a trabalhar. (E1).

Se o treinar e competir com lesão é tido como algo normal também o treino e competição com dor é banalizado, como nos refere a entrevistada $n^{\circ} 7$ :

É essa dor que nós temos de aprender a lidar com ela, porque enquanto não aprendermos vamos estar sempre a limitar o nosso treino e o nosso jogo porque não há volta a dar. Tentamos tratar o mais possível porque não passa. Uma tendinite vai estar sempre lá, é tentar saber lidar com ela. (E7).

As nossas atletas para além de considerarem a dor como algo inerente à prática desportiva, desenvolvem algumas estratégias para lidar com a dor e lesão, tais como o esconder e esquecer a dor e a lesão. 


\subsubsection{Esconder a dor}

Para Charlesworth e Young (2006), a dor e as lesões em ambientes desportivos masculinos e especialmente em contextos de elite não são vistas de uma forma favorável tanto por treinadores como por atletas. Por esta razão Young; Mcteer e White, (1994) argumentam que muitos atletas do gênero masculino tendem a esconder a dor. Porém, esta estratégia é também muito utilizada pelas mulheres atletas. Segundo Kotarba (2004 apud CHARLESWORTH; YOUNG, 2006), as atletas para além de tenderem a esconder e bloquear a dor referem-se à existência de uma dor rotineira à qual facilmente se habituam no seu dia-a-dia. Esconder a dor é uma das estratégias muito utilizadas pelas atletas, e este fato foi apontado por várias das nossas entrevistadas:

Escondo [...], só quando vejo que não dá mesmo é que paro. (E2).

Prefiro treinar com dor, omitir a dor, não dizer que me dói tanto como dói. (E2).

Escondo...é mais ou menos isso, até porque acabamos por viver com ela, e é uma coisa mais usual. (E7).

\subsubsection{Esquecer a dor}

Quando questionadas sobre o modo como toleram a dor e a lesão, algumas das nossas entrevistadas referiram que procuram esquecer, e/ou pensar noutra coisa ou simplesmente não pensar, como se pode observar através dos seus discursos:

Pensar, não penso praticamente em nada. (E1).

Tento pensar em outra coisa, ou no tempo que estou a fazer às vezes até conto as [...] que estou a fazer, para tentar esquecer a dor. É muito mais fácil quando nos tentamos esquecer da dor. (E5).

Ainda que sabendo que o treinar e/ou competir com dor e/ou lesão pode ser prejudicial para a sua saúde podendo mesmo levar ao aparecimento de lesões permanentes, nocivas para a saúde, as atletas 
continuam a fazê-lo. Quais serão então as razões para o fazerem. Que "forças" as levarão a agir desta forma?

\subsection{Pressões de OUTROS SIGNIFICANTES}

De acordo com a literatura (LISTON, et al., 2006; WADDINGTON, 2000; RODERICK, WADDINGTON; PARKER, 1999) as experiências de dor e lesão das atletas são melhor compreendidas no "contexto de uma rede de relações sociais que podem contribuir para a vontade dos atletas em jogarem lesionados, conhecendo ou não o risco de desenvolverem maior dor, lesões e possivelmente incapacidades físicas a longo prazo" (NIXON, 1996 apud CHARLESWORTH; YOUNG, 2004, p.167). Neste sentido, treinadores, colegas de equipa, bem como directores, tendem a surgir como os outros significantes que maior impacto têm na decisão dos atletas jogarem ou treinarem e competirem com dor ou ainda não totalmente recuperados de lesões.

Os treinadores são particularmente importantes nesta decisão, os quais muitas vezes não respeitam a dor dos atletas nem a sua reabilitação. Este fato foi relatado pela maioria das nossas entrevistadas como se pode observar através dos seguintes excertos:

Muitas vezes penso que não posso parar, porque depois fico em baixo de forma ou perco resistência, [...], mas pronto acontece com toda a gente, com todas as lesões. (E1).

Já me aconteceu estar com o pulso partido, e estou com gesso, e pedirem-me imenso para tirar o gesso para ir jogar.

Quem? (Entrevistador)

O treinador e o director da equipa. (E3).

Eu chego aqui e digo [...]'dói-me o ombro, não posso treinar, ou estou com uma lesão na virilha, hoje não dá, e tenho de parar uma semana'. Ele fica doido [treinador] [...] começa a resmungar comigo, a dizer 
que eu não tenho cabeça, que eu tenho é de treinar, que já não ia aos nacionais, não ia aos europeus, que ia embora do clube, que era uma baldas. (E5).

Para além do treinador, também o grupo de trabalho, os/as colegas de equipa parecem exercer alguma pressão sobre os atletas.

É por minha recompensa, e também pelo grupo de trabalho. Nós estamos num clube em que temos várias pessoas muito boas e isso influencia um bocado, para ficar como eles. A ajuda deles depois também nos incentiva, a ir buscar forças para continuarmos a treinar. (E4).

Através do discurso das nossas entrevistadas é evidente a existência de uma rede de relações sociais que teve impacto nas suas decisões para treinarem e competirem com dor e lesão. Ainda que estas não fossem "forçadas" a treinar e competir com dor e lesão estas atletas foram subtilmente persuadidas a esconderem a dor e a lesão. À semelhança do já observado em outros estudos (CHARLESWORTH; YOUNG, 2004; CHARLESWORTH; YOUNG, 2006), as nossas entrevistadas mostraram estar dispostas a aceitar os riscos associados ao treinar e competir com dor e lesão porque as redes de relações sociais de que elas fazem parte constroem tais experiências como algo natural.

\subsection{AMBIÇÃO/RECONHECIMENTO/SUCESSO}

Os/as atletas muitas vezes decidem continuar a treinar e a competir com dor e lesão com receio de ficarem "para trás" em relação aos/às colegas do grupo de trabalho. É também referido que os/as atletas tendem a tolerar, a esconder ou mesmo ignorar a dor e as lesões porque desejam atingir objetivos muito específicos e alcançarem determinados resultados. De acordo com Charlesworth e Young (2004), aqueles que estão envolvidos no desporto ao mais alto nível de rendimento, acreditam que ser um verdadeiro atleta significa lutar pela distinção e pela vitória, ainda que isso possa significar colocar em risco a sua saúde pelo fato de ignorarem as lesões e tolerarem a dor. 
Estes aspectos surgiram de forma evidente nos discursos das nossas entrevistadas:

Com lesões, e porque tenho provas em breve, e uma pessoa não pode parar com provas importantes para atingir os nossos objetivos. (E4).

As entrevistadas $n^{\circ} 5$ e $n^{\circ} 6$ apresentam este mesmo tipo de razões:

Muitas vezes, antes de entrar na água pego numa caneta e risco na mão o tempo que eu tenho de fazer para os mínimos, para os europeus. E sempre que estiver a pensar em desistir, olho para a mão e digo: 'não, eu tenho de fazer este tempo, tenho de fazer este treino para conseguir esse tempo. E é assim que conseguimos ultrapassar todos os dias as dores. (E5).

Mesmo com lesão ou não, eu estou aqui com um objetivo. A alta competição é assim, é a competição ao mais alto nível. E se nós queremos estar ao mais alto nível temos de treinar para isso. Temos de merecer as medalhas que depois podem vir. (E6).

O medo de perder o lugar na equipa ou na seleção é também uma das razões apontada por algumas das nossas entrevistadas para tolerarem a dor e ignorarem por vezes as lesões:

Tenho medo de perder o lugar na seleção, na equipa não. (E1).

Pode-se dizer que o gosto pelo desafio bem como o intuito de vencer o medo de ficar para trás, são dois grandes motivos apresentados pelas nossas entrevistadas quando questionadas sobre as razões pelas quais continuam a treinar e competir com dor e lesão.

\section{Considerações finaIS}

A informação obtida permitiu-nos verificar que as razões para as atletas treinarem e competirem com dor e lesão são quer de 
ordem interna quer de ordem externa. Se as pressões exercidas pelos treinadores, colegas do grupo de trabalho e até directores ajudam a moldar a atitude das atletas relativamente à dor e à lesão, também as pressões que as atletas exercem sobre si próprias, no sentido de atingirem os seus objetivos e alcançarem bons resultados, são particularmente importantes na forma como estas toleram a dor e tendem, muitas vezes, a ignorar a lesão.

Desde que iniciam a prática desportiva, independentemente da modalidade, as atletas são socializadas numa cultura desportiva que tende a normalizar e mesmo a banalizar o risco, a dor e a lesão. Como tal, para estas atletas, treinar, jogar, competir com dor e lesão é tido como algo normal e até como fazendo parte da "ética desportiva" (HUGHES; COAKLEY, 1991 apud NIXON II, 2004, p.87).

Podemos afirmar que nas relações de interdependência que as atletas mantêm com outras pessoas da configuração desportiva estas (atletas) são as mais vulneráveis. São, desta forma, particularmente vulneráveis a treinadores, médicos e directores que estão mais interessados em resultados e vitórias do que propriamente interessados e preocupados com o bem-estar físico e psíquico das atletas. Ainda que possuindo poder (pois não existe ninguém desprovido de poder), estas atletas são constrangidas por pessoas que têm relativamente mais poder, a agir e a pensar de formas que não agiriam ou pensariam se não estivessem sob compulsão. Os seus atos e os seus comportamentos são em muitos casos uma replicação das crenças e atitudes observáveis na vasta configuração desportiva.

Uma das maiores críticas de um estudo de caso prende-se com o fato dos resultados representarem apenas as ideias ou representações dos participantes. Reconhecemos que os resultados desta investigação evidenciam apenas as interpretações dos significados atribuidos às lesões e dores desportivas, expressos pelas nossas entrevistadas. No entanto, estando todos os autores ligados, em maior ou menor grau, à configuração desportiva portuguesa, e sendo um dos autores uma ex-atleta portuguesa internacional, 
podemos afirmar com alguma confiança que a informação recolhida e analisada se enquadra no contexto nacional e reflete a realidade desportiva portuguesa. 


\section{Experiences of pain and injury in portuguese women's sport}

Abstract: In contemporary sport an increasing value is being given to victory leading to a decrease in the importance given to simple participation. Having the goal of victory at all costs, many athletes are willing to train and compete with pain and injury. Most of the studies addressing the issue of pain and injury have focused on the experiences and feelings of pain and injury of male athletes; and on the pressures that act over these athletes, leading them to submit their bodies to pain and injury. However, experiences of pain and injury are no stranger to women athletes. This work has as its main goal understanding the reasons why female athletes, from different sports, accept and tolerate pain, and practice and compete while injured. It is also our purpose to inquire about the strategies used to manage pain and / or injury. Data was collected through seven semi-structured interviews with athletes from the following sports: swimming, volleyball, handball, judo, gymnastics, soccer and athletics. The women involved in this study, aged between 18 and 26 years old, were chosen because, at the time of this research, they were still in activity. The interviews were thematically analysed. Our data showed that during the period in which athletes were injured they felt frustrated, scared and with no self-esteem. Hiding, omitting and forgetting the pain and injury were the strategies mentioned by the athletes to manage pain and injury. In this study, as in previous studies, we identified and analyzed a culture of risk in elite sport that tends to normalize pain and injury.

Keywords: pain and injury, women's sports, performance 
Experiencia del dolor y lesión en el deporte femenino português

Resumen: En el deporte de hoy se valoriza la vitoria llevando a una desvalorización de la importancia a la simples participación deportiva. Con el objetivo de la vitoria de cualquier forma, muchos son los deportistas que presentan gran prontitud para entrenar y competir con dolor y lesión. La mayoría de los estudios que abordan la problemática del dolor y lesión se han centrado en las experiencias vividas del dolor de atletas hombres, en las presiones que actúan en esos atletas, llevándoles a someter sus cuerpos a ese dolor e lesión. Todavía, este fenómeno del dolor y de la lesión no es raro en las mujeres atletas. Así, este trabajo tiene como principal objetivo entender las razones que llevan deportistas de género femenino practicantes de diferentes modalidades a aceptar e tolerar el dolor y a entrenar y competir mismo lesionadas. Es también nuestra intención indagar acerca de las estrategias utilizadas por esas atletas para administrar el dolor y/o la lesión. Para la busca de información hicimos siete entrevistas a atletas de las siguientes modalidades: natación, voleibol, balonmano, judo, gimnastica, futbol y atletismo. Las mujeres envueltas en este estudio, con edad entre los 18 y los 26 años, fueran escogidas por el hecho de que en el momento de la investigación todavía se encontraban en actividad. La información obtenida fue sometida a técnica de análisis de contenido. En el periodo en que se encontraban lesionadas las atletas referían sentirse frustradas con miedo y sin autoestima. Esconder, omitir y olvidar el dolor fueran las estrategias señaladas por las atletas para administrar el dolor. En este estudio, así como en otros ya hechos, identificamos y analizamos una cultura de riesgo en el deporte de elite que tiende a normalizar el dolor y la lesión.

Palabras clave: dolor y lesiones, deporte femenino, rendimiento 


\section{REFERÊNCIAS}

AMARAL, L.; SANTOS, P.; FERREIRINHA, J. Caracterização do perfil lesional em ginástica artística feminina: um estudo prospectivo das ginastas Portuguesas de competição ao longo de uma época desportiva. Revista Portuguesa de Ciências do Desporto, Porto, v. 9, n. 1, p. 43-51, 2009.

BALE, J. The place of pain in running. In: LOLAND, S.; SKIRSTAD, B.; WADDINGTON, I. (Ed.). Pain and injury in sport. London: Routledge, 2006. p. 65-75.

CHARLESWORTH, H.; YOUNG, K. Why english female university athletes play with pain: motivations and rationalisations. In: YOUNG, K. (Ed.). Sporting bodies, damaged selves: sociological studies of sports-related injury. Amsterdam: Elsevier, 2004. p. 163-180.

Injuried female athletes: experiential accounts from England and Canada. In: LOLAND, S.; SKIRSTAD, B.; WADDINGTON, I. (Ed.). Pain and Injury in Sport. London: Routledge, 2006. p. 89-106.

CURRY, T.; STRAUSS, R. A little pain never hurt anybody: a photo-essay on the normalization of sport injuries. Sociology of Sport Journal, Edmonton, Canada, v. 11, n. 2, p. 195-208, 1994.

DOMINGUES, M: Treino proprioceptivo na prevenção e reabiltação de lesões nos jovens atletas. Motricidade, Vila Real, V. 4, n. 4, p. 29-39, 2008.

ELIAS, N. Introdução à sociologia. Lisboa: Edições 70, 1980.

GREEN, K. Researching Physical Education: Reflections on the Utility of SemiStructured Interviews. The Bases of Informed Decision Making for Sports Managers, Leicester, v. 7, p. 219-236, 1999.

HOWE, P. Welsh rugby union: pain, injury and medical treatment in a professional era. In: YOUNG, K. (Ed.). Sporting bodies, damaged selves: sociological studies of sports related injury. Amsterdam: Elsevier, 2004. p. 237-248.

LISTON, K. et al. Managing pain and injury in non-elite rugby union and rugby league: a case study of players at a British University. Sport in Society, London, v. 9 , n. 3, p. 388-402, 2006.

LOLAND, S.; SKIRSTAD, B.; WADDINGTON, I. Pain and Injury in Sport. London: Routledge, 2006.

MAGUIRE, J.; PIKE, E. Injury in Women's Sport: Classifying Key Elements of 'Risk Encounters'. Sociology of Sport Journal, Edmonton, Canada, v. 20, n. 3, p. 232$251,2003$.

NIXON, H. Accepting the risks of pain and injury in sport: mediated cultural influences on playing hurt. Sociology of Sport Journal, Edmonton, Canada, v. 10, n. 2, p. 183-196, 1993. 
The relationship of friendship networks, sports experiences, and gender to expressed pain thresholds. Sociology of Sport Journal, Edmonton, Canada, v. 13 , n. 1 , p. $78-86,1996$.

NIXON II, H. Cultural, structural and status dimensions of pain and injury experiences in sport. In: YOUNG, K. (Ed.). Sporting bodies, damaged selves: sociological studies of sports-related injury. Amsterdam: Elsevier, 2004. p. 81-97.

PIKE, E. Risk, pain and injury: a natural thing in rowing? In: YOUNG, K. (Ed.). Sporting bodies, damaged selves: sociological studies of sports-related injury. Amsterdam: Elsevier, 2004. p. 151-162.

REGO, F.; REIS, M.; OLIVEIRA, R. Lesões em ginastas portugueses de competição das modalidades de trampolins, ginástica acrobática, ginástica artística e ginástica rítmica na época 2005/2006. Revista Portuguesa de Fisioterapia no Desporto,S. Domingos de Rana, v. 11, n. 21, p. 21-59, 2007.

RODERICK, M. The work of professional football: a labour of love? London: Routledge, 2006.

RODERICK, M.; WADDINGTON, I.; PARKER, G. Managing injuries in professional football: a study of the roles of the club doctor and physiotherapist. Leicester: Centre for Research into Sport and Society, 1999.

ROESSLER, K. Sport and the Psychology of Pain. In: LOLAND, S.; SKIRSTAD, B.; WADDINGTON, I.(Ed.). Pain and Injury is Sport. London: Routledge, 2006. p. 3448.

WADDINGTON, I. Sport, Health and Public Policy. In: YOUNG, K. (Ed.). Sporting bodies, damaged selves: sociological studies of sports-related injury. Amsterdam: Elsevier, 2004. p. 288-307.

Sport, Health and Drugs. London E New York: E \& FN Sport, 2000.

WADDINGTON, I.; MURPHY, P. Drugs, sport and ideologies. In:DUNNING, E.; ROJECK, C. (Ed.). Sport and leisure in the civilizing process. Basingstoke: Macmillan, 1992. p. 36-64.

YOUNG, K. Sporting Bodies, Damaged Selves. Oxford: Elsevier, 2004.

YOUNG, K.; MCTEER, W.; WHITE, P. Body Talk: Male Athletes Reflect on Sport, Injury and Pain. Sociology of Sport Journal, Edmonton, Canada v. 11, n. 2, p. 175-194, 1994.

Endereço para correspondência:

pinclaudia@gmail.com

Recebido em: 24.11.2010

Aprovado em: 13.12.2011

ovimento, Porto Alegre, v. 17, n. 04, p. 101-121, out/dez de 2011. 
